\section{Family Matters}

In Book Club this month we discussed a novel: Family Matters by Rohinton Mistry, ${ }^{1}$ shortlisted for the Booker Prize in 2002 (figure 1). Set in Delhi, it begins with Nariman Vakeel, a 79-year-old man with Parkinson's disease. Early in the book, he falls and breaks his leg, and so has to move in with his daughter Roxana, her husband and their two sons. It explores the effects that this has on all members of the family over the next few months and years.

Although this is a relatively long novel (over 500 pages) it is beautifully written, painting an intimate and sympathetic picture of the family, as well as the background scene of Delhi, with fascinating

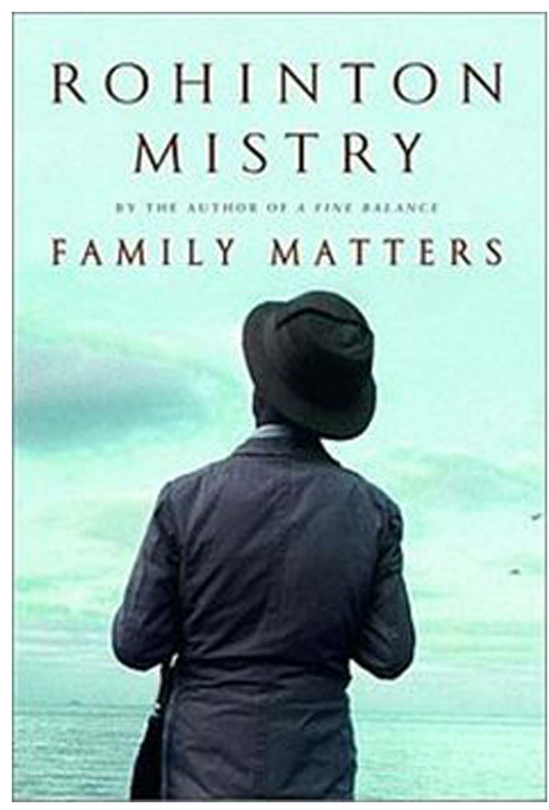

Figure 1 Cover of Family Matters (source: http://upload.wikimedia.org/ wikipedia/en/thumb/a/a1/FamilyMatters. jpg/220px-FamilyMatters.jpg). and colourful descriptions of a big and bustling city in modern India. At times, the vivid writing almost transports the reader there.

The book raised many interesting practical and clinical points for our discussion. Its core is a description of the indignity of becoming old and disabled, and having to rely on others. Much of this is not specific to Parkinson's disease, and could be applied to many slowly progressive disabling diseases. The book also illustrates the catastrophic effects for a person with Parkinson's disease of retiring to bed. Once Nariman becomes bedbound after his fracture, he never leaves his bed again, which makes uncomfortable reading in the knowledge of what good physiotherapy, occupational therapy, and neuro-rehabilitation can do in this setting. In addition, it is an excellent account of what it is like to be a carer: unglamorous, hard work, largely behind closed doors and so unappreciated by most people, and often unpleasant and smelly.

The book poignantly describes Nariman's loss of autonomy as a consequence of his Parkinson's disease and his leg fracture; his doctors and family talk about what they think would be best for him-sometimes in front of him—but without directly involving or consulting him. Their paternalistic style of medicine differs from today's practice of our discussants; the book reminded us why we have moved away from this approach to medicine.

Nariman's family, and particularly his step-daughter Coomy, use him as a bargaining tool-a situation commonly encountered in medical setting. The novel tells us about the family history and dynamics that are behind these actions, which can help us to understand them, even if we are not sympathetic.
The book shows a strong moral component as well. The consequences of people's acts come back to them later: deceptive behaviour eventually leads to retribution. Nariman's behaviour to his wife and his stepchildren after he is first married affects how they treat him when he is unwell. Roxana's husband tries to atone for his own actions by turning to religion, which has its own impact upon the family. The framework of this gives another layer of complexity to the novel, adding interest and provoking thought.

This book deals not only with the effects of disease upon a family, but also of the effects of the family on the disease. It is a graphic account of growing old, living with regret, and losing one's independence; as such it was an interesting and thought-provoking book for Neurology Book Club. It is also a beautiful and evocative novel, and well worth the effort of reading.

Twitter Follow Katharine Harding at@drkatharineh

\section{Katharine Harding}

Department of Neurology, University Hospital of Wales, Cardiff CF14 4XW

Correspondence to Dr Katharine Harding, katharineharding@doctors.org.uk

Competing interests None.

Provenance and peer review

Commissioned internally peer reviewed.

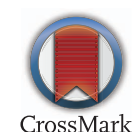

To cite Harding K. Pract Neurol 2015;15:85.

\section{REFERENCE}

1 Mistry R. 2002. Family Matters. London: Faber and Faber Ltd. 